\title{
LA POLÍTICA DE FILIPO V EN LA PROPONTIDE: EL CASO DE LA CIUDAD DE CÍOS
}

\author{
F. JAVIER GÓMEZ ESPELOSÍN \\ Universidad de Alcalá de Henares
}

\begin{abstract}
En este artículo se intenta analizar el fragmento de Polibio concerniente a los acontecimientos de Cíos del año 202, tratando de incardinar los hechos dentro del contexto histórico general del momento y entre los objetivos centrales trazados por Filipo $\mathrm{V}$ para el desarrollo de su política exterior. Se presta una especial atención a los disturbios internos que vivió la ciudad y a la posible incidencia de los mismos en la secuencia de los hechos posteriores. Todo ello sin olvidarnos de la decisiva importancia que el peso de una tradición histórica desfavorable al monarca macedonio ha tenido en la configuración definitiva de unos acontecimientos confusos y difíciles de evaluar por la escasez de los datos con que contamos al respecto.
\end{abstract}

In this paper is analysed the polybian fragment about the events in the bythinian town of Cius 202 B. C., in an attemp to incardinate them in the historical context of the time and in the - supposedly - planned aims of Philip's foreign policy. A special attention is placed on the inner troubles in the city and about its character. Indeed the role of a biased tradition in our knowledge of the case is also considered.

Las figuras de los dos últimos monarcas macedonios, Filipo V y su hijo Perseo, han atraído la atención de los historiadores, tanto de los antiguos como de los modernos. La proyección internacional que alcanzó su política y dentro de ella su particular relación con Roma, que tras el 168 significó la desaparición del reino como tal entidad para pasar a convertirse en una mera dependencia de la República, son motivos más que suficientes que avalan con creces este interés. Sin embargo quizá ha sido principalmente Filipo $\mathrm{V}$ el que ha suscitado una literatura más generosa y abundante a causa de su poderosa personalidad, del complejo entramado de su política interna, de sus cambiantes relaciones con los demás estados griegos y con las otras monarquías helenísticas, y especialmente -como era de esperar- de sus dos conflictos bélicos con Roma. Todo ello está de sobra justificado si tomamos en consideración la duración e importancia de su reinado, que sin duda constituye una de las piezas clave del enorme puzzle que ante nuestros ojos compone el panorama histórico de todo este período (1). Polibio, que constituye una fuente de primer orden para toda esta época, dedica al monarca una atención preferente a lo largo de su narrativa y nos ha legado de su persona una visión contrapuesta y en muchos momentos contradictoria al haber mezclado de forma no siempre muy ortodoxa la alabanza de sus cualidades innatas de gobernante y estadista de primera línea con reproches frecuentes sobre algunas

(1) Sería difícil reunir aquí todos los trabajos que conciernen a la figura de Filipo $\mathrm{V}$, si tenemos en cuenta que resulta casi imposible hallar una monografía sobre el mundo helenístico que no dedique un buen número de páginas a su persona. Una simple consulta al índice de nombres propios confirmará lo que decimos. La obra que sigue todavía hoy siendo canónica a este respecto es la monografía de F. W. Walbank, 1940. Un buen ejemplo de lo que decimos es la reciente monografía de Gruen, 1984, en la que las referencias a Filipo ocupan casi columna y media del índice de nombres. 
facetas de su conducta, que a partir de la célebre metabolé experimentaba por su carácter - verdadera piedra angular de todo el retrato psicológico de su personalidad-, se convirtieron en pautas fijas de un modo de comportamiento censurable (2).

Esta degradación moral de Filipo $\mathrm{V}$, según nos refiere Polibio, tuvo sus inicios en el incidente de Mesenia del año 215. En esa ocasión se hizo con el dominio de la acrópolis de la ciudad aprovechando en su favor las disensiones internas que enfrentaban a las dos facciones de la ciudad en lucha por el poder, después de haber sabido insuflar ánimos a unos y otros y haberles incitado así a su mutua destrucción. A partir de entonces, todas sus empresas empezaron a salirle mal y lo que antes habian sido adhesiones generalizadas y alabanzas pasaron de golpe a convertirse en críticas acerbas, muestras evidentes de temor y recelos bien fundados hacia cualquiera de sus acciones (3). Relacionado de alguna manera con esta faceta de su carácter se halla el tópico que ha hecho de Filipo un defensor y adalid de las masas helénicas y por tanto el sostenedor impenitente de cualquier clase de movimiento popular, con una política de claro corte demagógico que tenía como único objetivo atraer de su lado a la gran mayoria de los estados griegos, que se encontraban por entonces desgarrados por terribles luchas internas (HOLLEAUX, 1935, 197-198, 202-203, 228-229, 234: Id., 1978, 146).

Ya ha quedado demostrado lo erróneo de tales consideraciones a la vista de la escasa u nula base documental que nuestras fuentes ofrecen a tal efecto y por tanto no nos parece necesario volver de nuevo sobre el particular si no es con la sana intención de resumir el nudo central de toda la cuestión, operación que quizá puede no resultar impertinente para el tema que nos va a ocupar en las páginas que siguen. Los trabajos de Erich Gruen y Doron Mendels sobre la política de Filipo en muchos de los casos que Polibio censura con acritud su comportamiento, han establecido de forma clara la finalidad que perseguía el monarca macedonio con tales intervenciones (GRUEN, 1981, 169 y ss. MEN-

(2) Pedech, 1964, 104-109, 118, 231-232, sobre la célebre metabolé de Filipo.

(3) Pol. VII, 10-11, sobre los hechos de Mesenia; 12-14a, sobre su metabolé. Mendels, 1980, sobre los acontecimientos de Mesenia. Roebuck, 1941, 78 y ss., en general sobre todo el asunto mesenio.
DELS, 1977, 155 y ss.). Sus deseos por conseguir el dominio y la hegemonía sobre el conjunto de los estados griegos le llevaron a poner en práctica una política marcada en palabras de Gruen por «pragmatism and adaptabililty» y cuyo fundamento esencial continuaba siendo, como ha probado Mendels, «to support the aristocratic factions in Greece, as his predecessors had» (GRUEN, 1981, 181: MENDELS, 1977, 155). Un apoyo consistente a aquellos elementos dirigentes de las ciudades que se le mostraron afectos fue el sistema que Filipo V utilizó de forma más habitual para extender su zona de influencia dentro del ámbito político griego y hasta tal punto fue así que tenemos incluso algunos ejemplos concretos que pueden servir de adecuado contrapunto a cualquier suposición en favor de un respaldo decidido de Filipo a las masas o a lo que pudiera considerarse facción popular.

Los sucesos de Mesenia a los que hemos hecho alusión son una buena muestra de lo que decimos y así de hecho han sido considerados por Gruen y Mendels en sus respectivos trabajos (GRUEN, 1981, 171-173 y MENDELS, 1977, 159-161). Pero todavía podría añadirse otro caso quizás más significativo como es el de la actuación de Filipo en la ciudad focidia de Elatea, que constituye también un buen ejemplo de los métodos que el monarca macedonio utilizó cuando las circunstancias le obligaron a ello o ciertas consideraciones de tipo estratégico le impulsaron a actuar sin muchas contemplaciones o miramientos. Según el testimonio de Pausanias se hizo con el control de la ciudad gracias al sometimiento de la mayoría de la población por el terror y al soborno previo de sus elementos dirigentes, a quienes había sabido ganarse mediante la concesión de $\delta \omega \rho \varepsilon \alpha ́$ (Paus. X, 34, 3-4. PASSERINI, 1948, 8395). Existe también un caso que quizá podría agregarse a esta lista ante las dudas que surgen sobre el lado de la contienda que adoptó Filipo en su intervención y es precisamente el tema que nos ocupará en las páginas que siguen.

Los acontecimientos a que hacemos referencia tuvieron lugar en el año 202 en Cíos, una ciudad situada en la Propóntide. La ciudad había sido presa de convulsiones internas que concluyeron al parecer con el triunfo de un tal Molpágoras, figura que sólo conocemos por el relato de los hechos que se nos ha conservado en uno de los fragmentos de Polibio procedentes de los Excerpta Constantiniana y por una breve referencia del léxico Suda bajo la 
denominación $\delta \eta \mu \alpha \gamma \omega \gamma$ uno de los escasos testimonios relativos a las acciones de Filipo $\mathrm{V}$ en esos decisivos momentos que procedentes del historiador griego han sobrevivido hasta nuestros días. Polibio nos describe a Molpágoras como un individuo hábil en el manejo de la palabra y de la acción política al que sin embargo desacreditaban su tendencia demagógica y su ambición de poder. Al parecer había incitado a la multitud con-

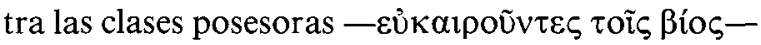
con la finalidad de someterlas a su dominio y a continuación procedió a la ejecución de unos, al destierro de otros y -como complemento esperadoa la confiscación de todos sus bienes para uso público. Por medio de todas estas acciones consiguió establecerse en el poder convirtiendo su gobierno en una verdadera tiranía de hecho-

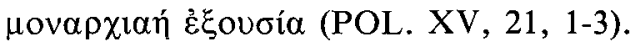

Sin duda estas breves y confusas referencias sobre los acontecimientos internos de la ciudad no nos permiten ir muy lejos en nuestras deducciones. Sin embargo en el texto de Polibio siguen al fragmento mencionado unas reflexiones del propio historiador sobre las desdichas sufridas por los cianeos, que de acuerdo a su forma habitual de proceder eleva al terreno general, insistiendo sobre la imprevisión que caracteriza la conducta de los hombres, a pesar de haber sido causa de numerosos males, en contraposición al modo de comportamiento seguido por los animales en parecidas circunstancias, que huyen espantados ante un peligro, si han visto caer en él a otros miembros de su especie. Ya en el tema concreto que le ocupa, Polibio se sorprende de cómo los hombres, aún a pesar de que han visto perecer a muchas ciudades por haber aplicado esta clase de política, vuelven de nuevo a sucumbir en el engaño. Es en este punto de su narrativa cuando Polibio introduce el relato de la intervención de Filipo V en los asuntos de la ciudad en foma de un encendido reproche sobre su comportamiento que viene a concretar en tres puntos fundamentales. En primer lugar por haber dado su apoyo a Prusias I de Bitinia, un monarca al decir de Polibio que no respetaba los pactos contraídos con sus vecinos. En segundo lugar por haber causado un daño injusto a una ciudad

(4) Pol. XV, 21-23; Léxico Suda s.v. Mo $\lambda \pi \alpha ́ \gamma o p \alpha \varsigma \delta \eta \mu \alpha \gamma \omega-$ $\gamma 1 \kappa o ́ c$. Holleaux, 1935, 291 n.1, Walbank, 1940, 114 y ss., Id, 1967,474 , sobre la fecha de los acontecimientos. Berve, 1967 , 427 , Mendels, $1977,166-168$, Id, 1982, 92-93, en general sobre los hechos. griega, lo que le iba a suponer la difusión de su mala fama por todo el orbe helénico. Y por último por haber injuriado con su conducta a los embajadores de unas ciudades - que dice haber mencionado con anterioridad- que habían acudido a su presencia para mediar por la suerte de los cianeos (5). El pasaje objeto de nuestra atención concluye con la relación de todas las enemistades que Filipo se granjeó en estos momentos a causa de lo sucedido en la ciudad de Cíos. Fueron éstas las de los rodios, ante los que hubo de enviar precisamente un embajador que le defendiera de las acusaciones en su contra, los etolios, al haber transgredido su alianza con la ocupación de Lisimaquea, Calcedonia y Cíos, y por fin la de su propio aliado y pariente el rey Prusias, que recibió como único beneficio una ciudad arrasada (POL. XV, 23, 6 y ss.).

Toda la discusión subsiguiente sobre los acontecimientos ha tomado como base en buena medida la visión de las cosas que el mismo Polibio nos ofrece. El comportamiento irracional e injustificado de Filipo no habría tenido otro objetivo que el de desposeer a los etolios de estas importantes plazas estratágicas de los estrechos. Sin embargo, como ya anticipamos, no está del todo clara cuál fue la posición que adoptó Filipo respecto a la pretendida revolución de Molpágoras ni cuál pudo ser el papel que estas circunstancias pudieron jugar en la destrucción final de la ciudad (6). La reconstrucción de los hechos que ha llevado a cabo De Sanctis parece que está en buena consonancia con los pormenores del relato polibiano. Se refiere así a la existencia previa de una guerra entre la ciudad de Cíos y Prusias y al posterior asedio de la villa por parte de Filipo, que habría acudido allí como en calidad de aliado de su pariente. La ciudad fue por fin tomada al asalto aún a pesar de las buenas palabras que el rey había dado a los enviados rodios que habían intervenido en su favor (DE SANCTIS, 1969, 6-7). Sin embargo el estudioso italiano no alude para nada

(5) Walbank, 1967, 476, admite que es probable que se tratase de Rodas, Atenas y Quíos, que ya habían intentado ser neutrales durante la primera guerra macedonia. Rodas de hecho aparece citada más adelante por haber enviado una embajada a Filipo, Pol. XV, 22, 5 y ss.

(6) Walbank, 1967, 475, afirma «which side the kings (Filipo y Prusias) supported is unknown; but Philip, who had been moving away from the possesing classes for a variety of reasons, cannot be assumed to have been necessairily opossed to the elements represented by Molpagoras». 
en su reconstrucción de los hechos a la situación interna de la ciudad y es más que probable que la misma tuviese una repercusión notable en los acontecimientos que siguieron según se desprende del largo comentario que Polibio parece haberle dedicado.

En su estudio más reciente del caso, Mendels se limita por contra a abordar la cuestión de cuál pudo haber sido la posición que Filipo adoptó ante los hechos, declarándose favorable a la hipótesis que supone que fueron los oponentes a las «reformas» de Molpágoras quienes gozaron del respaldo macedonio, al menos por lo que cabe deducir del propio testimonio de Polibio. Deja sin embargo como consideración marginal el intento de situar lo sucedido dentro del contexto histórico general de la política de Filipo, renunciando asimismo a establecer una secuencia cronológica que se ajuste lo más posible al relato entrecortado que tenemos de los hechos (7).

Lo que aquí nos proponemos no es otra cosa que un intento de situar los hechos en su contexto histórico adecuado, valorarlos de acuerdo con los datos que Polibio nos proporciona y por último esbozar los móviles que presidieron la conducta de Filipo, en vista del hecho de que las explicaciones más comunes, que toman como base una política de agresión expansionista y el propio desequilibrio psicológico del monarca, nos parecen cuando menos algo simplistas y desde luego se deja sentir en ellas la influencia de la visión negativa que nuestras fuentes de información dejan traslucir al respecto (8).

Si consideramos en primer lugar lo sucedido en el interior de la ciudad — que ocupa además secuencialmente la primera parte del relato de Polibio tal y como nos ha llegado- todo parece indicar que se trató aparentemente de un fenómeno de características revolucionarias. Molpágoras se alzó con el poder gracias al apoyo de la mayoría y las víctimas principales del nuevo régimen fueron los ricos, que sufrieron ejecuciones, destierros y confiscaciones de

(7) Mendels, 1977, 166, «I think that Philip supported the well-to-do faction when he gained control of the city by destroying Molpagoras revolutionary faction».

(8) De Sanctis, 1969, 8, alude a la «sua precipitazione e violenza, se non provocò, affrettò e inasprí la guerra inevitavile... cosí rispondente del resto al suo carattere». Walbank, 1940, 258 y ss., con similares consideraciones. Briscoe, 1973, 38, «it, remains necessary to investigate Philip's motives for his aggressive actions at this times). sus propiedades (9). Sin embargo a pesar de las apariencias persisten algunas dudas que nos obligan a plantearnos más de cerca la pertinencia más o menos justificada del término revolución para calificar los acontecimientos vividos en Cíos.

Para empezar no encontramos entre las medidas adoptadas por Molpágoras, al menos destacadas como tales, dos de los postulados fundamentales de los fenómenos revolucionarios del mundo antiguo, que constituían además unas reivindicaciones continuas de las clases bajas: la cancelación de las deudas y la distribución de las tierras (FUKS 1966, 446-447 e Id., 1974, 77-78). Por lo que respecta al segundo de los puntos quizá se podría replicar que la riqueza fundamental de la ciudad estaba basada en el comercio, dada la naturaleza de Cíos, sin embargo resulta muy poco creíble imaginar una ciudad griega que no dispusiera de tierras colindantes en mayor o menor medida, sobre todo si tenemos en cuenta que en inscripciones procedentes de ciudades de la zona minorasiática aparecen mencionados con frecuencia hechos tales como la concesión de tierras por parte de los monarcas de la zona en beneficio de las ciudades o el otorgamiento del derecho de posesión o compra en favor de individuos particulares que han llevado a efecto alguna acción beneficiosa para la ciudad (10).

Por el contrario la mención de confiscaciones de bienes no constituye un factor determinante para calificar al régimen surgido de los disturbios internos como revolución. Esta medida aparece frecuentemente entre las diversas secuelas que arrastraban las luchas faccionales en el interior de las ciudades griegas cuando uno de los dos bandos en lucha por el poder conseguía de forma efectiva la supremacía sobre sus rivales, sin necesidad de que se produjese consiguientemente un vuelco completo de la situación socio-económica anterior, pasando a desempeñar el poder los oprimidos y las clases bajas de la

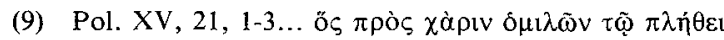

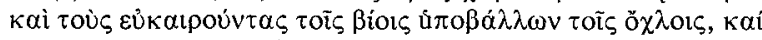

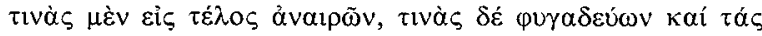

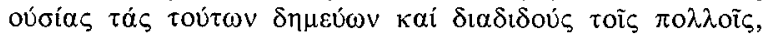

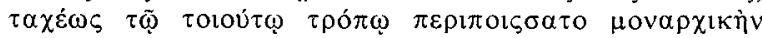

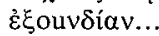

(10) Ogis 218 lin.108; 220 lin.16; 221 lin.9 y ss., 30 y ss.; 228 lin.8; 229 lin.4; 265 lin.21; 305 lin. 19; 309 lin. 3; 316 lin. 10, son todos ejemplos de ciudades de la zona asiática en los que se menciona la existencia de tierras ligadas al dominio de la ciudad. Finley, 1973, 173 y ss. Id, 1981, 38 y ss., en general sobre el problema. 
población. Hallamos este tipo de medidas entre las actuaciones de Licisco en Etolia o de Cárope en el Epiro, cuando se hicieron con el control de sus respectivos estados tras los acontecimientos que siguieron a la victoria romana sobre Perseo en Pidna (LIV.XLV, 28, 7 y POL. XXXII, 5). Incluso es también probable que se diesen medidas semejantes en los desórdenes de Beocia en el último tercio del siglo III o entre las medidas de emergencia adoptadas por los estrategos aqueos durante los difíciles momentos que precedieron al Bellum Achaicum del 146 (11).

Otro tanto sucede con las ejecuciones y proscripciones, ambas hechos frecuentes que solían acompañar el final de las contiendas políticas en el interior de las ciudades griegas (GEHRKE, 1985). Asi hallamos por doquier desterrados que se han visto obligados a huir de sus patrias de origen después del triunfo de sus enemigos políticos y tampoco faltan las ejecuciones sumarias si bien en algunos casos se tuvo el cuidado de hacer intervenir de forma «legal» a la asamblea, como sucedió en el Epiro con Cárope, en Beocia con Bráquilas o en la misma Atenas con León (GÓMEZ ESPELOSÍN, 1985, 235 y ss.). Sin embargo en la práctica totalidad de los casos no se trató de un enfrentamiento frontal entre las clases posesoras y la gran masa de los desheredados, sino más bien de una oposición interna entre las diferentes facciones constituidas fundamentalmente por elementos de la clase dirigente, que pugnaban por el predominio en el estado. En muchas ocasiones no obstante uno de los contendientes, quizá menos seguro de sus fuerzas, recurría a buscar el apoyo de la multitud granjeándose su favor mediante un hábil empleo de la demagogia. Sin embargo es más que probable que siempre supiesen mantener en un punto determinado el alcance de las medidas adoptadas para obtener el apoyo mayoritario, de manera que nunca significasen la completa subversión del status quo anterior y sin duda entre estos procedimientos estaba la confiscación de los bienes de sus rivales y el consiguiente reparto ocasional que servía como apaciguamiento temporal de unas aspira-

(11) Pol. XX, 6, sobre los hechos de Beocia; Feyel, 1942,279 y ss. Cloche, 1943, 243 y ss., Aymard, 1946, 313 y ss., Mendels, 1977, 161-165 y Gruen, 1981, 174-176, en general sobre estos acontecimientos. Pol. XXXVIII, 15, sobre el Bellum Achaicum. Fuks, $1970,83-84$, sobre las medidas adoptadas. ciones a más largo plazo pero quizá no ensartadas en ninguna forma organizada (12).

Volviendo al caso que nos ocupa, no parece que Molpágoras se hiciera con el poder de forma violenta por lo que se desprende del relato de Polibio, siendo ésa la forma más común de acceso al poder en los regímenes revolucionarios (KRAMNICK, 1972, 35 y ss.). Parece más bien que se produjo como resultado de un triunfo electoral obtenido en el tradicional juego democrático de la pólis, según podemos deducir del posterior comentario de Polibio a los hechos. Censura en efecto la $\alpha \beta$ ou $\lambda i \alpha$ y la $\kappa \alpha \kappa о \pi о \lambda \iota \tau \varepsilon i ́ \alpha$ de los cianeos, que les ha llevado

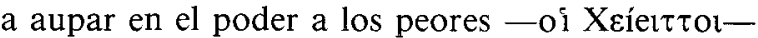
y al sometimiento consiguiente de quienes se les opo-

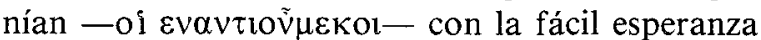
de llegar a compartir sus riquezas (POL. XV, 21, 4-5). Habría que sumar a este dato la ya citada reflexión sobre la falta de previsión de los hombres y sobre la facilidad con que son presa de la seducción que les lleva a pensar que pueden solucionar su mala situación presente mediante la ejecución de medidas de esta clase.

Pero no es sólo el tono general de estas reflexiones el que nos hace suponer que se pudo haber tratado de un caso más de lucha faccional interna entre los elementos de las clases dirigentes. También el propio vocabulario utilizado por Polibio parece apuntar en esa misma dirección. Se nos dice por ejemplo que fue de forma voluntaria como los cianeos llegaron a esta situación - $\dot{\varepsilon} \theta \varepsilon \lambda o v \tau \eta ́ v-$ pro-

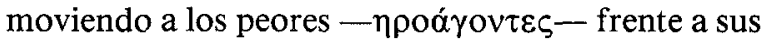
oponentes con la finalidad de conseguir unos objetivos que no eran sino una trampa $-\delta \varepsilon \dot{\varepsilon} \varepsilon \alpha \rho-$. En este último sentido hay que resaltar que el verbo relacionado con este término - $\delta \varepsilon \lambda \varepsilon \alpha ́ \zeta \omega-$ aparece empleado en Polibio solamente en tres contextos que no dejan lugar a dudas sobre el cariz definitorio de los acontecimientos. Se trata de la seducción de la masa por aquellos que pretenden hacer uso de su apoyo para sus propios objetivos políticos (13). Éste

(12) En este sentido resultan ilustrativas las reflexiones de Maquiavelo sobre la forma de acceder al poder o su comportamiento inicial en el mismo en su obra el Príncipe.

(13) Pol. VI, 9, 6, los más ricos por ambición al poder dilapidan su patrimonio empleando todos los medios posibles para corromper y engañar al pueblo. XXXII, 6, 2, la multitud seducida por Cárope en Fénice. XXXVIII, 11, 11, las últimas medidas del Bellum Achaicum.. 
es aparentemente también el caso de Molpágoras. Polibio le calificaba, como dijimos anteriormente, como hombre habilidoso tanto de palabra como en

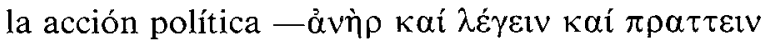
ikavõs y esta caracterización nos remite muy posiblemente hacia un miembro de las clases dirigentes de la ciudad, dado que entre otras cosas resulta difícil de imaginar que calificativos semejantes se puediesen emplear para definir a un individuo de baja extracción social, tanto por el propio posicionamiento socio-político de nuestro historiador como por las escasas oportunidades que una persona procedente de los estamentos inferiores habría hallado para hacer uso de tales cualidades. De hecho lo que Polibio le reprocha es su aîpeoıs demagógica y su ambición de poder, cualidades ambas negativas para el buen desempeño del gobierno siempre entendido desde la óptica del status existente, ya que le condujeron a irrogarse un poderío tiránico, que constituía uno de los temores principales a los ojos de las clases dirigents (MOSSE, 1969, 133 y ss.). La no alusión de Polibio a su condición social baja nos aparece también como significativa si tenemos en cuenta que sí es mencionada de forma explícita y como dato relevante en otros casos señalados como el de Querón de Esparta, Heraclides al tarentinoconsejero de Filipo V-o el de los pretendientes reales Alejandro Balas y Andrisco (14).

Hay también un factor de la política exterior de la ciudad que parece avalar nuestra hipótesis. Cíos mantenía una relación de isopoliteía con la confederación etolia y en la ciudad se hallaba un estratego etolio, que muy probablemente debió de apoyar a la facción de Molpágoras, dado que estaba presente en esos momentos en la ciudad (POL. XV, 23, 9-10). Sabemos que había una cierta tendencia de la política exterior etolia que consistía en apoyar iniciativas de esta clase en las ciudades griegas, especialmente tras su toma de contacto con Cleómenes y su revolución (PEDECH, 1964, 154-158 y MENDELS, 1982, 89-90 n.16). Sin embargo no conoce-

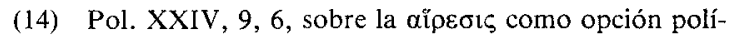
tica. De las 81 veces que aparece el término en el texto de Polibio, 44 parecen convenir bien con este significado, al igual que el adjetivo $\alpha$ i $\rho e \varepsilon \tau \imath \sigma \tilde{\eta} \varsigma$ que aparece 4 veces, Mauersberger, 1956, 26-27. Pedech, 1964, sobre la diferencia entre púoıs y ai peoıs, 229 y ss. Pol. XXIV, 7, 2, sobre Querón de Esparta, XIII, 4, 4 , sobre Heraclides. Los testimonios sobre los falsos pretendientes plantean el problema de que no están conservados en el propio texto de Polibio, aunque resulta probable que provengan de él. mos ningún caso en el que fuesen ellos mismos los que fomentaran fenómenos de similares características, limitándose más bien a dar su apoyo a sus partidarios, que muchas veces a causa del prestigio de sus oponentes y de la opción política adoptada se vieron obligados a adoptar un posicionamiento de tipo demagógico como único medio viable de contrapesar el predominio de sus rivales políticos dentro del estado (15). Debemos recordar además en este mismo sentido que dentro de la propia Etolia había fracasado pocos años antes un intento legislativo de reforma que propugnaba una cierta cancelación de las deudas. Sus promotores, Escopas y Dorímaco, encontraron una fuerte resistencia entre sus oponentes, a cuya cabeza figuraba un tal Alejandro Isio, personaje que será precisamente uno de los portavoces de las demandas etolias ante Filipo en la conferenia de Nicea (16). Dada la relevancia política de que al parecer gozaba este personaje en Etolia no parece probable suponer que desde el lado etolio se respaldase una iniciativa de carácter revolucionario y más en una ciudad como Cíos que era miembro aliado de la confederación. Quizá puede resultar significativa en este mismo sentido la presencia de un rico mercader de Cíos, llamado Herodoto, en Calcis junto al líder local proetolio Eutímidas, en unos momentos en los que se intentaba auspiciar desde el lado etolio una revuelta en la ciudad favorable a sus intereses, diez años después de los hechos que comentamos (LIV.XXXV, 37, 5). La conexión entre ambos resulta ciertamente tentadora, dado el nexo común existente que constituye la presencia etolia, y por tanto quizá no es muy descabellado imaginar que el mencionado Herodoto se hubiese encontrado entre quienes apoyaron el régimen de Molpágoras. Tras la intervención de Filipo se vio obligado a escapar de la ciudad y buscó refugio en Calcia, lugar idóneo ya que existía en esa ciudad una importante facción proetolia. Si las cosas se hubiesen desarrollado de esta forma, tendríamos un argumento más en favor de la tesis que mantenemos, a saber que dentro de la facción de Molpágoras se hallaban también elementos de las clases

(15) Gómez Espelosín, 1985, 33-35 (Cineta en el 220), 7274 (Elide contra el tirano Aristótimo), 74-75 (Mantinea en el 226), 126 (Calcis en el 192), 127 (Atenas en el mismo año), 224-226 (Opunte en el 197), 246-248 (Demetríade en el 192).

(16) Pol. XIII, 1-1a, sobre el intento de Escopas y Dorimaco. Pol. XVIII, 3-4 y LIV.XXXII, 33, 10 y ss., sobre la intervención de Alejandro Isio. 
dirigentes de la ciudad, de la misma forma que ocurría en los demás conflictos de esta clase que se dieron en el resto de Grecia.

Pero una vez llegados aquí, cómo se articula lo sucedido en el interior de la ciudad con el resto del relato entrecortado y fragmentario de Polibio. Cómo explicar la intervención de Prusias primero y después de Filipo. Cuáles fueron en definitiva las razones de fondo que motivaron el comportamiento de Filipo en la ciudad. Ya hemos hecho referencia anteriormente a la explicación formulada por De Sanctis. En ella se hacía alusión a la existencia de un conflicto abierto entre la ciudad y Prusias y la posterior llamada a Filipo por parte del monarca bitinio, en la base a su doble relación de alianza y parentesco. Siguiendo esta línea quizá debemos intentar buscar las causas del enfrentamiento en el deseo de Prusias de incorporar la ciudad a sus dominios, objetivo que ahora se había visto complicado con la presencia etolia en la zona (17). Esta idea podría estar avalada por hechos como el que Filipo hiciese recaer sobre las espaldas de los etolios las culpas últimas del destino sufrido por la ciudad, acusándoles ante Flaminino de hacer objeto de botín lo que ya pertenece a otros, aludiendo con ello quizá a la legitimidad del ataque de Prusias, por hallarse la ciudad dentro de los límites de su reino (POL. XVIII, 4-5). Es probable que tras el triunfo de la facción de Molpágoras, muy posiblemente con el respaldo etolio, Prusias viese peligrar su hegemonía en la zona, sobre todo a la vista de que dos puntos clave de la región como Lisimaquea y Calcedonia ya se hallaban también del lado etolio. De esta forma desencadenó el conflicto y llamó a Filipo para que acudiera en su ayuda. El reproche de Polibio a Prusias por no respetar los pactos con sus vecinos y la expresión referente al sometimiento por Filipo

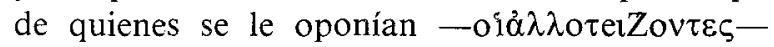
parecen apoyar esta visión de las cosas y las claras intenciones de Prusias de anexionarse la ciudad (POL. XV, 22, 1-3).

Hemos de considerar también en esta misma dirección el intento de mediación rodia en el asunto, enviando embajadores a Filipo junto con los de otras ciudades para impedir que la ciudad fuese destruida

(17) Ogis 340, Prusias volvió a fundar la ciudad cuando Filipo se la cedió bajo el nombre dinástico de Prusa del Mar. Rostovtzeff, 1953, 532-533, sobre la importancia de las salidas al mar del reino bitinio. Habitch, 1957, col. 1088 y ss., sobre la política general de Prusias. y quizá también que cayera en manos de Prusias. La escueta frase con que Polibio alude a las circunstancias concomitantes $\dot{\varepsilon} \kappa \tau \tilde{\omega} \vee \pi \varepsilon \rho \varepsilon \varepsilon \sigma \tau \dot{\omega} \tau \omega \vee \kappa \alpha \alpha \tilde{\omega} \nu$ no nos permite ir muy lejos en nuestras deduccciones, si bien parece que se hace referencia a unos peligros inminentes que en esos momentos se cernían sobre Cíos (18). Rodas siempre mantuvo una constante preocupación por preservar libres de peaje los estrechos de manera que su importante comercio póntico no encontrase dificultades, como lo muestra su conflicto del 220 con Bizancio, para el que por cierto se alió hasta con el mismo Prusias, que de esta forma mostraba ya por entonces un gran interés por el dominio de la zona (19). Sin embargo en los momentos presentes las cosas habían cambiado y ya no coincidían, siquiera de forma circunstancial, los intereses bitinios y rodios. Prusias era por entonces aliado formal de Filipo - figuraba de hecho entre los adscripti de la paz de Fénice- y debió contemplar la posibilidad de incorporar la ciudad a su reino con la fácil colaboración de su aliado. El aparente desencanto de Prusias cuando tras la intervención de Filipo hubo de resignarse a recibir una ciudad saqueada y vacía, parece en efecto reflejar la contrariedad experimentada por el rey bitinio a la vista de unas expectativas iniciales mucho más prometedoras (POL. XV, 23, 10). Polibio censura con indignación la actitud de Filipo ante los embajadores rodios, sin embargo es muy probable que exagere como actos de burla y menosprecio lo que no era sino una deliberada política dilatoria ante la expectativa del curso que iban tomando los acontecimientos, muy similar a la que ya había practicado al parecer con el embajador egipcio que el regente de Tolomeo V, Agatocles, había enviado a Macedonia con el objeto de afianzar los lazos de amistad que unían a ambos gobiernos (20).

Con este último punto nos introducimos de lleno en la tercera de las cuestiones planteadas como es

(18) Pol. XV, 22, 4. Incluso podría haber sucedido que la tiranía de Molpágoras ya hubiese sido derribada cuando se produjo el ataque de Filipo a la ciudad, si consideramos la frase que en Léxico Suda sigue a lo contenido en el fragmento polibiano:

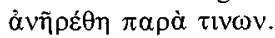

(19) Miltner, 1935, 1-15, sobre la importancia de la libertad de los estrechos para el desarrollo normal del comercio rodio. Will, 1982, 45-46, en general sobre el tema y el desarrollo de la guerra.

(20) Pol. XV, 25, 13; Briscoe, 1973, 38 y Will, 1982, 109, sobre la embajada. 
la de los objetivos que Filipo V perseguía con sus acciones de estos momentos. Para abordar el asunto nos hallamos de entrada con dos importantes problemas. Uno es el acuerdo pactado entre Filipo y Antíoco III para repartirse los despojos del entonces maltrecho imperio lágida. Otro lo constituye la hostilidad hacia Filipo que evidencian las fuentes de información que Polibio pudo manejar para los asuntos que consideramos, que se viene a sumar así a su ya habitual posicionamiento no muy favorable hacia el monarca (PEDECH, 1964, 101-102, 105106, 108-109, 116, 223-224, 231-232 y WALBANK, 1940, 278-281). Dejando a un lado la cuestión sobre cuáles pudieron haber sido los términos del susodicho acuerdo, lo que parece claro en todo este asunto son las intenciones de Filipo de conseuir unas posiciones estratégicas en la zona norte del Egeo y en especial en la Propóntide, según nos las dejan adivinar sus acciones de estos momentos. El interés macedonio por toda esta región había sido ya antes uno de los rasgos centrales de la política tradicional de la casa real macedonia que siempre albergó el deseo de asegurarse una posición estratégica similar al menos a la que ya gozaban los demás reinos helenísticos. Lisímaco había desarrollado parte de su actividad principal en la zona e incluso en la lucha por su dominio había encontrado la muerte Tolomeo Cerauno.

Problablemente Filipo pretendía continuar esta misma línea de actuación, que estaba además perfectamente en consonancia con las necesidades estratégicas de defensa de su propio reino frente a la amenaza que representaban los tracios. No debemos olvidarnos de la situación geopolítica que ocupaba Macedonia como reino balcánico, que necesitaba imperiosamente mantener bajo su control aquellas zonas que daban acceso al reino desde el norte. Dentro de esta misma línea es muy probable que pocos años antes Filipo hubiese llevado a cabo una campaña contra los tracios, llegando en su penetración hasta el río Hebro (21). Su interés por Lisimaquea, a la que pretendía defender de los tracios en su defensa ante Flaminino, que fue más tarde aban-

(21) Walbank, 1981, 83-84, en general sobre la política macedonia. Id., 1940, 270-271, sobre la importancia de la frontera norte para la preservación del reino. Niese, 1893-1903, II, 571 n. ${ }^{\circ} 2$ y Schmitt, 1964, 234, sobre la posible campaña contra los tracios. Walbank, 1940, 258-259, sobre la imitación de la política seguida por Filipo II. Pol. XVI, 28, sobre la perseverancia de Filipo. donada por Filipo y destruida por aquéllos (POL. XVIII, 51, 7 y LIV.XXXIII, 38) y su apoyo a Bizancio unos años más adelante con la expresa finalidad -así al menos lo subraya Polibio- de inquietar a los reyezuelos de la zona (POL. XXII, 14, 11), constituyen una muestra evidente de la puesta en práctica de esta clase de política defensiva.

Es igualmente muy probable que Filipo, aún a pesar del pacto, tuviese muy en cuenta las intenciones manifiestas de Antíoco de recuperar los dominios tradicionales de.la casa real seleúcida, que implicaban a una buena parte de la zona por la que Filipo mostraba su interés, y tratase por tanto de afianzar sus posiciones de cara al eventual avance seleúdida en la región, que más adelante se produjo (WILL, 1982, 178 y ss.). En este sentido cabe entender toda su actuación en las ciudades independientes de la zona como Lisimaquea, Calcedonia, Perinto y la propia Cíos. Sin embargo los métodos utilizados para conseguir estas posiciones no fueron siempre los mismos a pesar de la falsa apariencia que producen los reproches etolios generalizados sobre todas estas ciudades en la reunión con Flaminino. Si en las tres primeras lo que operó fue simplemente un cambio de alianzas por medio de tratados que fortalecieran su posición jurídica ante una probable negociación ulterior con Antíoco, no sucedió lo mismo en el caso de Cíos (22). Su comportamiento allí fue bien diferente al que tenemos constatado por ejemplo con Lisimaquea con la que al parecer llevó a cabo un tratado en términos favorables para la propia ciudad (23), y quizá las causas de esta diferencia de trato haya que buscarlas en las razones que el mismo Filipo expone como defensa en su comparecencia ante Flaminino y en el comentario de Polibio sobre la reacción que el curso de los hechos provocó en el rey. Filipo se defiende de los ataques etolios replicando que su intervención en la ciudad fue para ayudar a su aliado, hecho que no le hacía por tanto sentir vergüenza alguna por lo sucedido, pues su actuación a más de haberse producido de forma legítima le había provisto de pri-

(22) Bickermann, 1939, 345-348 y Jones, 1940,98 y ss., sobre la práctica habitual seguida en estos aspectos por las monarquías helenísticas.

(23) Oikonomos, 1915, 2-7 n. ${ }^{\circ} 1$ y Bickermann, 1939, 349 , nos presentan el texto del tratado. Holleaux, 1935, $291 \mathrm{n} .^{\circ} 1$, sobre el susodicho tratado. Robert, 1955, 270, reconoce que «il y avait eu traité d'alliance entre le roi et la ville et non pas occupation brutale et sans formes». 
sioneros y botín en abundancia y le había llevado a concluir en su opinión una gesta digna y brillante (POL. XVIII, 4-5 y XV, 22, 1-2). Desde luego no le faltaban razones para la euforia. Había incrementado los recursos de su reino, tan necesitado en esos momentos desde el punto de vista financiero a causa de los cuantiosos gastos de su política militar, y había dado buenos pasos en su empeño por conseguir una potente flota con la que poder controlar de modo eficaz el Egeo (24). Y si no conservó la ciudad en su poder sino que como era de rigor se la cedió a Prusias, también de esa forma cumplió otro de sus objetivos, como era el reforzamiento de las posiciones de un enemigo potencial de Antíoco, paso que completó más tarde con la cesión añadida de Mirlea (STRAB. XII, 4, 3=C 563). Estas acciones se incluían también en la misma línea de política preventiva antes señalada, de cara a contrapesar en el futuro las más que probables acciones bélicas del seleúcida en la zona (25).

Juzgadas de este modo, las acciones de Filipo durante esos momentos nos aparecen como parte integrante de todo un plan premeditado de mucho más amplias miras, tendente muy posiblemente a recuperar lo que se consideraban dominios tradicionales de la casa real macedonia. Da la impresión que para llevar a efecto el mismo siguió unos pasos bien medidos de cuyo alcance era perfectamente consciente. No contravino con sus acciones ningún tratado internacional — como el de Fénice- - ni proporcionó con su conducta unos motivos suficientes desde el punto de vista jurídico que justificasen el inicio de una guerra en su contra por cualquiera de las grandes potencias del momento. Sólo Rodas rompió las hostilidades de forma declarada tras los sucesos de Cíos, pero es posible que Filipo no buscase un enfrentamiento directo con la isla, al menos en la forma descarada que nos quiere hacer creer Polibio. Así parece indicarlo el hecho de que se molestase en enviar un embajador ante la asamblea

(24) Walbank, 1940, 112, debemos recordar que Filipo había perdido su flota en el 214 y tenía por tanto una imperiosa necesidad de recuperarla. Rostovtzeff, 1935, 692 y ss. y Walbank, 1981,83 , sobre el incremento de los recursos del reino.

(25) Walbank, 1940, 108, sobre el interés de Filipo por la carrera de Antíoco III, donde se afirma que «the revival of Syria threatened the balance of power betwen Egypt, Syria and Macedon». Holleaux, 1954, 150 y ss., sobre la politica internacional del momento. Errington, 1971, 336-354 y Will, 1982, 114 y ss., sobre el pacto con Antíoco. rodia que le defendiera de las acusaciones que en su contra se estaban vertiendo alli, algo de lo que Filipo debía ser conocedor (POL. XV, 23). Hasta entonces las relaciones mutuas se habían mantenido en ciertos niveles de cordialidad, como parecen probarlo el testimonio de una inscripción en la que se

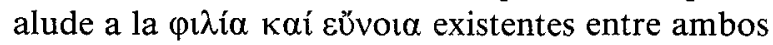
gobiernos o las mutuas embajadas que con motivo de los acontecimientos de Cíos se enviaron por ambos lados (BMI III $441=$ HICKS 182). Fue además a raíz de lo ocurrido en la ciudad bitinia cuando Rodas decidió considerar a Filipo como su enemigo y a emprender por tanto los consiguientes preparativos bélicos (POL. XV, 23, 6). Es muy probable que la guerra contra la piratería cretense que Rodas había emprendido poco antes supusiera una cierta interferencia en los planes de Filipo, quien no sólo auspiciaba su práctica por medio de su agente Dicearco, sino que como es bien sabido gozaba en Creta de un amplio reconocimiento (26). Sin embargo esta circunstancia no había sido determinante para la ruptura definitiva entre ambos como sí lo fueron los acontecimientos de Cíos. Quizá Filipo trataba de mantener la situación en el punto que estaba antes de la ruptura con su embajada exculpatoria a la isla. De otra forma para nada habría servido a no ser que supongamos en su conducta un alarde de cinismo político considerable, cuya finalidad práctica - y todos la suelen tenerse nos escapa. De hecho la indignación existente en Rodas en contra de Filipo por lo sucedido en Cíos, parece, tal cual nos lo deja vislumbrar el relato de Polibio, el resultado de haberse visto confirmadas entre la mayoría de la población unas sospechas, que hasta esos momentos solamente albergaban los decididos adversarios del rey, sobre unos hechos que, al menos por lo que puede colegirse de la propia información con que contamos, no estaban del todo confirmados como verídicos (POL. XV, 23, 4).

No debemos olvidar de qué clase de fuentes pudo haber obtenido Polibio su información sobre los acontecimientos referidos. Parece probable que fuesen los historiadores de la isla, Zenón o Antístenes, a tenor de la implicación directa de los intereses de su patria en lo sucedido y de la presencia de embajadores rodios en el lugar de los hechos, testigos

(26) Holleaux, 1920, sobre el papel desempeñado por el etolio Diceardo. Walbank, 1940, 109-111, sobre la utilización de la piratería por Filipo. Id., 1940, 67, sobre la presidencia del rey sobre la liga cretense. 
inmejorables por tanto de primera mano de lo ocurrido (ULLRICH, 1896, 36 y ss. y WALBANK, $1967,474)$. Ello hace que la visión de las cosas haya sufrido alguna deformación, sobre todo si consideramos la actitud posterior de la isla hacia Filipo, después del menoscabo flagrante que sus intereses habían sufrido a manos del rey (VAN GELDER, 1900, 122 y ss.). Por su parte, Polibio incluyó los hechos dentro de un contexto más amplio, ya de propia factura, en el que no sólo volvía de nuevo a la carga con sus habituales reflexiones sobre las consecuencias nefastas que implica el malgobierno de una ciudad y sobre la escasa atención que los hombres prestan a los errores cometidos con anterioridad, sino que situaba estas acciones de Filipo en la línea de comportamiento temerario e irracional que se había iniciado tras los sucesos de Mesenia, que como se ha dicho ya supusieron el comienzo de la ostensible mutación de su carácter (PEDECH, 1964, 112). Por lo demás resulta también harto sospechoso que de todas las acciones de Filipo de esos momentos nos halla llegado únicamente el fragmento relativo a Cíos y en cambio prácticamente nada de sus restantes empresas en las ciudades vecinas antes señaladas. Quizá lo que sucedió en la ciudad bitinia constituía el punto negro que se prestaba de forma más clara a ser explotado en detrimento de la fama de Filipo y a esta razón se deban en buena parte el énfasis y la insistencia puestos en él por una tradición hostil a la figura del monarca (27).

\section{BIBLIOGRAFÍA}

AYMARD, A., 1946, «La Grèce centrale au 111 siècle av. J. C.», Revue historique, 196, 287-316.

BREVE, H., 1967, Die Tyrannis bei den Griechen, Munich 2 vols.

BICKERMANN, E., 1939, «La cité grecque dans les monarchies hellénistiques» Revue de Philologie, 65, 335-349.

(27) Hemos tratado con mayor extensión todo el problema de la política de Filipo $V$ en los momentos previos al desenlace de la segunda guerra macedonia en otro lugar.
BRISCOE, J., 1973, A Commentary on Livy Books $X X X I-X X X I I I$, Oxford.

CLOCHE, P., 1943, Thébes de Béotie, Paris.

DE SANCTIS G., 1969, Storia dei Romani, Florencia vol. IV.

ERRINGTON, R. M., 1971, «The Alleged Syro-Macedonian Pact and the Origins of the Second Macedonian War», Athenaeum 49, 336-354.

FEYEL, M., 1942, Polybe et l'histoire de la Béotie au III siècle av.nôtre ère, París.

FINLEY, M. I., 1973, Economía de la Antigüedad, trad. cast. FCE, Méjico 1974.

- 1981, La Grecia antigua. Economía y Sociedad, trad. cast. Crítica, Barcelona 1984.

FUKS, A. 1966. «Social Revolution in Greece in Hellenistic Age», Parola del passato, 3, 437-448.

- 1970. «The Bellum Achaicum and its Social Aspects» Journal of Hellenic Studies 90, 78-89.

- 1974. «Patterns and Types of Social-Economic Revolution in Greece from the fourth to the Second Century B. C.» Ancient History 5, 51-81.

GEHRKE, H. J., 1985. Stasis. Untersuchungen zu den inneren Kriegen in den griechischen Staaten des 5 und 4 Jahrhundert $v$. Chr.

GÓMEZ ESPELOSIN , F. J. 1985. Rebeliones y conflictos internos en las ciudades del mundo helenístico, Alcalá de Henares-Zaragoza.

GRUEN, E. S. 1981. «Philip V and the Greek Demos» Ancient Macedonia. Studies in honour of Ch. F. Edson, Institute for Balkan Studies, Tesalónica. 169-182.

- 1984. The Hellenistic Wordl and the Coming of Rome, Londres-Berkeley.

HABITCH, Ch. 1957. Pauly Wisowa s. v. «Prusias» XXIII 1.

HOLLEAUX, M. 1920. «L'expedition de Dikaiarchos dans les Cyclades et sur l'Hellespont» Revue des Etudes Grecques 33,223 y ss.

- 1935. Rome, la Gréce et les monarchies hellénistiques au III siècle avant J. C. (273-205), París.

- 1954. «Rome and Macedon: the Romans against Philip» Cambridge Ancient History vol. VIII. Cambridge.

JONES, A. H. M., 1940. The Greek City from Alexander to Justinian, Oxford.

KRAMNICK, I. 1972. «Reflections on Revolution: Definition and Explanation in Recent Scholarship» History and Theory 11, 26-63.

MAQUiavelo, N. El Príncipe, trad. cast. Bruguera, Barcelona 1984.

MAUERSBERGER, A. 1956-1975. Polybios Lexicon, Berlín.

MENDELS, D. 1977. «Polybius, Philip V and the SocioEconomic Question in Greece» Ancient Society 8, 155-174.

- 1980. «Messene 215 B. C. An Enigmatic Revolution» Historia 29, 246-250.

- 1982. «Polybius and the Socio-Economic Revolution in Greece (227-146 B. C.)» L'Antiquité Classique 51, 86-110.

MILTNER, F. 1935. «Die Meerengenfrage in der griechischen Geschichte» Klio 28, 1-15.

MOSSE, Cl., 1969. La Tyrannie dans la Grèce antique, París. NIESE, B. 1893-1903. Geschichte der griechischen und makedonischen Staaten seit der Schlacht bei Chaeronea, Gotha 3 vols.

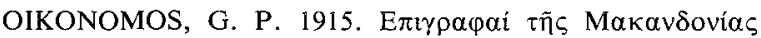
Atenas.

PASSERINI A. 1948. «La condizione della cittá di Elatea dopo la seconda guerra macedonica in una nuova iscrizione» Athenaeum 35, 83-95.

PEDECH P. 1964. La méthode historique de Polybe, París. ROBERT L. 1955. Hellenica 10. 